\title{
A Hybrid Method Based on Feature Fusion for Breast Cancer Classification using Histopathological Images
}

\author{
Emre Dandı1 $^{*}$, Ali Osman Selvi ${ }^{2}$, Kerim Kürşat Çevik $^{3}$, Mehmet Süleyman Yıldırım${ }^{4}$, Süleyman Uzun ${ }^{5}$ \\ ${ }^{1}$ Department of Computer Engineering, Faculty of Engineering, Bilecik Seyh Edebali University, Bilecik, Turkey (ORCID: 0000-0001-6559-1399) \\ ${ }^{2}$ Department of Computer Technology, Vocational School, Bilecik Şeyh Edebali University, Bilecik, Turkey (ORCID: 0000-0002-9532-0984) \\ ${ }^{3}$ Department of Management Information Systems, Faculty of Applied Sciences, Akdeniz University, Antalya, Turkey (ORCID: 0000-0002-2921-506X) \\ ${ }^{4}$ Department of Computer Technology, Söğüt Vocational School, Bilecik Şeyh Edebali University, Bilecik, Turkey (ORCID: 0000-0002-3998-1542) \\ ${ }^{5}$ Computer Engineering, Faculty of Technology, Sakarya University of Applied Sciences, Sakarya, Turkey (ORCID: 0000-0001-8246-6733)
}

(International Symposium on Multidisciplinary Studies and Innovative Technologies (ISMSIT) 2021 - 21-23 October 2021)

(DOI: 10.31590/ejosat.1018309)

ATIF/REFERENCE: Dandıl, E., Selvi, A.O., Çevik, K.K., Yıldırım, M.S. \& Uzun, S. (2021). A Hybrid Method Based on Feature Fusion for Breast Cancer Classification using Histopathological Images. European Journal of Science and Technology, (29), $129-137$.

\begin{abstract}
Breast cancer is the most common type of cancer in women today, and it ranks second after lung cancer with a very high mortality rate. If it is detected late, the treatment of breast cancer becomes very difficult. Although there are various methods for the detection of breast cancer, there is still a need for auxiliary diagnosis and treatment methods. In this study, a hybrid method is proposed to investigate the development of basal-like breast tumors and classify basal-like breast cancer types using histopathological images. In the study, firstly, appropriate features that support the accurate classification between tumor and non-tumor regions are extracted from histopathological images. Then the dataset is created by combining the obtained features. In the last stage of the study, the classification of images is carried out by using bag of words (BoW) and deep neural networks (DNN) techniques in a hybrid manner. Generally, immunohistochemical markers are used for this classification, but the performance of these markers remains at $60 \%$. The performance of the classification accuracy of the proposed system is increased with the proposed hybrid classifier based on feature fusion. As a result of the study, 94.5\% classification accuracy is achieved on the training set, while $80.8 \%$ classification accuracy is succeed on the test set. As a result, it is verified that successful results are achieved in the classification of basal-like breast cancer on histopathological images using the proposed hybrid method based on feature fusion.
\end{abstract}

Keywords: Breast cancer, Classification, Histopathological images, Deep neural networks, Bag of words, Feature fusion.

\section{Histopatolojik Görüntüler Kullanarak Göğüs Kanseri Sınıflandırması İçin Özellik Birleştirmeye Dayalı Melez Bir Yöntem}

$\ddot{\mathbf{O z}}$

Günümüzde kadınlar arasında en sık görülen kanser türü meme kanseridir ve akciğer kanserinden sonra oldukça yüksek bir ölüm oranına sahip olarak ikinci sırada yer alır. Geç tespit edilmesi durumunda ise meme kanserinin tedavisi oldukça zor bir duruma gelmektedir. Meme kanserinin tespiti için çeşitli yöntemler bulunmasına karşın, halen yardımcı tespit ve tedavi yöntemlerine olan ihtiyaç duyulmaktadır. Bu çalışmada, histopatolojik görüntüler kullanılarak bazal benzeri meme tümörlerinin gelişimini incelemek ve bazal benzeri meme kanserleri türlerini sınıflandırmak için melez bir sistem önerilmektedir. Yapılan çalışmada, ilk önce tümörlü ve tümörlü olmayan bölgeler arasında doğru sınıflandırmayı destekleyen kullanışlı özelliklerin çıkartılması sağlanmıştır. Daha sonra, elde edilen özelliklerin birleştirilmesi ile veriseti oluşturulmuştur. Çalışmanın son aşamasında ise, kelime çantası (bag of words) ve

* Corresponding Author: Bilecik Seyh Edebali University, Faculty of Engineering, Department of Computer Engineering, Bilecik, Turkey (ORCID: 0000-0001-6559-1399), emre.dandil@bilecik.edu.tr 
derin sinir ağları (deep neural networks) modelleri hibrit bir biçimde kullanarak görüntülerin sınıflandırma işlemi gerçekleştirilmiştir. Literatürde bu sınıflandırma için immünohistokimyasal belirteçler kullanılmaktadır, fakat bu belirteçlerin başarımları ise \%60 seviyelerinde kalmaktadır. Bu çalışmada, histopatolojik görüntülerden elde edilen özellikler birleştirilerek, önerilen melez sınıflandırıcı ile sistemin sınıflandırma doğruluğu başarımının artırılması sağlanmıştır. Gerçekleştirilen çalışma sonucunda, eğitim kümesi ile \%94.5 sınıflandırma doğruluğuna ulaşılırken, test kümesi ile \%80.8 sınıflandırma doğruluğu başarılmıştır. Böylece, histopatolojik görüntüler üzerinde bazal benzeri gögüs kanserinin sınıflandırılmasında özellik birleştirmeye dayalı önerilen melez yöntem ile başarılı sonuçlara ulaşıldığı doğrulanmıştır.

Anahtar Kelimeler: Göğüs kanseri, Sınıflandırma, Histopatolojik görüntüler, Derin sinir ağları, Kelime çantası, Özellik birleştirme.

\section{Introduction}

According to global cancer statistics in a study including 185 countries, cancer is the second-leading cause of death worldwide after heart diseases (Sung et al., 2021). In addition, according to the data of the World Health Organization (WHO), breast cancer is the most common cancer in women worldwide contributing to $25.4 \%$ of the total number of new cancer cases. Moreover, breast cancer has the second mortality rate after lung cancer (Han et al., 2017). According to a research conducted by The American Cancer Society in 2021, it is estimated that approximately 281,550 new cases of invasive breast cancer will be diagnosed in women in the United States, 49,290 new cases of ductal carcinoma will be diagnosed, and 43,600 women will die because of breast cancer (ACS, 2021). Worldwide, a recent report shows that 2,261,419 new cases of breast cancer were diagnosed in one year and 684,996 people died from breast cancer (Sung et al., 2021). These numbers are expected to increase year by year.

Traditional methods such as mammography, ultrasound and magnetic resonance (MR) imaging are used in the diagnosis of breast cancer (Dand1l \& Serin, 2020). Although these auxiliary imaging methods are used in the diagnosis of breast cancer, histopathological images are preferred for accurate diagnosis. Pathologists make definitive diagnosis of the disease with biopsy, but detailed examination with the help of a microscope can take a longer time. In addition, sometimes the accurate result cannot be achieved in cases due to the expert-based reasons such as fatigue and lack of experience. For these reasons, technologies such as machine learning, deep learning and image processing have been frequently used in the histopathological examination of tissue samples in recent years (Wang et al., 2016). For the diagnosis of breast cancer, experts examine the textural features, detect the differences in the normal breast structure, and assess the tissues stained with Hematoxylin and Eosin (H\&E) with a microscope. Technologies that can perform computer-aided automatic diagnosis have started to be used frequently since they can be used as a faster and helpful tool in cancer detection. Classification accuracy can be increased and differences of opinion among experts can be reduced by these methods (Kumar et al., 2020).

Breast cancer is divided into five different subtypes as Luminal A, Luminal B, normal-like, HER-2 overexpression and basal-like (Badowska-Kozakiewicz \& Budzik, 2016; Dai et al., 2015). Basal-like tumors are known as a subtype of breast cancer defined by gene and protein expression. Basal-like tumors are seen at a high rate among all types of breast cancer. Basal-like breast cancer is prevalent among younger women. These tumors show aggressive behavior and have a poor prognosis (Çevik et al., 2021). Although basal-like tumors are characterized by using many distinctive features, there is not yet a fully proposed system for both defining subtypes of breast cancer at the clinical level and systematically classifying them. Although immunohistochemical markers are used in the classification of basal-like breast cancer, the performance of these markers is not very high (Badowska-Kozakiewicz \& Budzik, 2016).

In the previous studies proposed for the diagnosis of breast cancer, early detection and treatment have been shown to significantly improve survival rates of the patient (Jones et al., 2015). It is often preferred to use microscopic images for the diagnosis and treatment of breast cancer (Ibrahim et al., 2015). Pathologists assess the clinical findings of the disease as well as the microscopic examination at the diagnosis stage (Badve et al., 2011). In this process, the classification of the type of breast cancer and the accurate determination of its stage may also vary according to the professional experience of the physicians. For this reason, it is very important to develop and propose computer-aided automatic secondary auxiliary tools that physicians can use in their decision-making processes.

Computer-aided automatic diagnosis systems have an important place in the assessment of medical images (Öztürk \& Akdemir, 2018). Especially in recent years, with the increase in cancer cases, automatic analysis of histopathological images has become prominent (Sertel et al., 2010). In order to achieve higher accuracy in automatic detection/diagnosis systems, it has become widespread to combine different methods and therefore to use hybrid methods. These methods facilitate the process by helping the expert in the decision-making process (Mikhaylov \& Bakhshiev, 2017). A brief review of some of the studies previously proposed for the diagnosis of breast cancer based on the analysis of histopathological images is presented in Table 1.

In this study, a hybrid system is proposed for the classification of basal-like breast cancer types using histopathological images. Texton features, network features, morphometric features and gray-level co-occurrence matrix (GLCM) features were extracted from histopathological images, similar to the previous studies proposed for the detection of breast cancer. Then the features were combined using feature fusion. Unlike previous studies, in the final stage of the study, the classification process of basal-like breast cancer images was carried out using a hybrid model obtained by combining bag of words (BoW) and deep neural networks (DNN) models. The rest of this paper is organized as follows: In Section II, the material and method contents are detailed within the scope of the study, and sub-sections such as the general block diagram of the model, the used methods, feature extraction techniques, and the used dataset are mentioned. In Section III, experimental research results and discussion are presented. In this section, the findings are presented in detail, the results are evaluated graphically. In the last section, the results obtained from the study and the future studies are presented. 
Table 1. A brief review of some of the previous studies proposed for the diagnosis of breast cancer

\begin{tabular}{|c|c|c|}
\hline (Reference, Year) & Method & Evaluation \\
\hline $\begin{array}{l}\text { (Abdel-Zaher \& Eldeib, } \\
\text { 2016) }\end{array}$ & $\begin{array}{l}\text { Liebenberg Marquardt learning function, DBN-NN } \\
\text { (deep belief network path) }\end{array}$ & High accuracy was achieved \\
\hline $\begin{array}{l}\text { (Öztürk \& Akdemir, } \\
\text { 2018) }\end{array}$ & $\begin{array}{l}\text { SVM (support vector machine), k-NN (k-nearest } \\
\text { neighbors), LDA (linear discriminant analysis) and } \\
\text { boosted tree }\end{array}$ & $\begin{array}{l}\text { The most successful results are in the combination of SFTA } \\
\text { (Segmentation-based Fractal Texture Analysis) and Boosted Tree }\end{array}$ \\
\hline $\begin{array}{l}\text { (Mohammed et al., } \\
\text { 2018) }\end{array}$ & Multi-fractal dimension features & A high level of sensitivity was achieved \\
\hline $\begin{array}{l}\text { (Khameneh et al., } \\
\text { 2019) }\end{array}$ & $\mathrm{CNN}$ and SVM & $\begin{array}{l}\text { The proposed method was shown to outperform when comparing } \\
\text { other approaches }\end{array}$ \\
\hline (Budak et al., 2019) & $\begin{array}{l}\text { FCN (fully convolutional network), Bi-LSTM (bi- } \\
\text { directional long short term memory) }\end{array}$ & $\begin{array}{l}\text { The performance on BreakHis database was found to be better } \\
\text { than other methods }\end{array}$ \\
\hline (Yan et al., 2020) & Hybrid convolutional and recurrent DNN & High performance with average accuracy highlighted \\
\hline (Kumar et al., 2020) & VGGNet-16 based CNN & $\begin{array}{l}\text { For CMTHis and BreakHis databases, } \\
\text { high average accuracy achieved }\end{array}$ \\
\hline (Dandil \& Serin, 2020) & DNN & $\begin{array}{l}\text { The results were compared using four different pre-trained } \\
\text { backbones such as DenseNet201, Inception V3, ResNet50 and } \\
\text { Xception }\end{array}$ \\
\hline (Çevik et al., 2021) & DNN with transfer learning & High accuracy was achieved \\
\hline (Zewdie et al., 2021) & CNN-based ResNet50 pre-trained network & High accuracy was achieved \\
\hline
\end{tabular}

\section{Material and Method}

In this proposed study, a hybrid system based on feature fusion was designed for the classification of basal-like breast tumors on histopathological images. Firstly, useful features that support the accurate classification of tumor and non-tumor regions were extracted. The dataset was created by combining the obtained features. In the last stage of the study, the classification of breast cancer was provided by using BoW and DNN models in a hybrid manner. In order to test the developed system, publicly-available datasets were used. The block diagram of the stages carried out in the study is shown in Figure 1 .

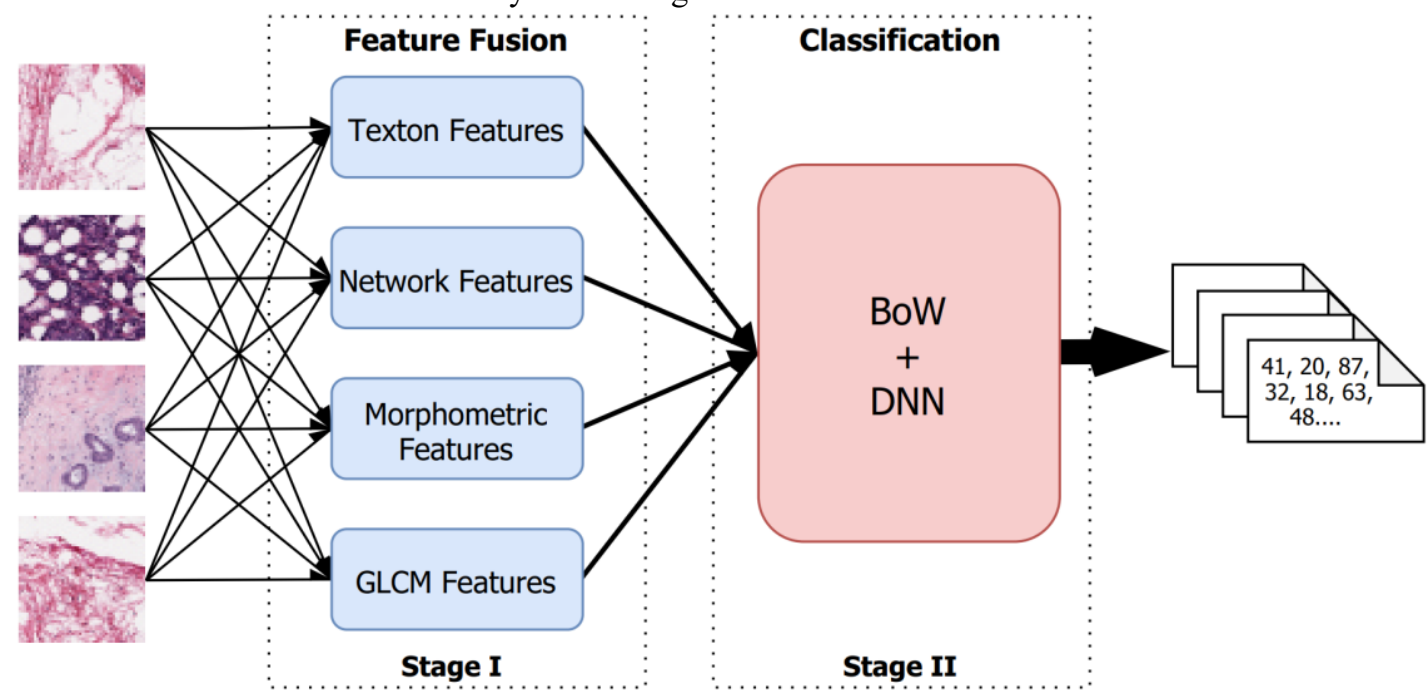

Figure 1. Block diagram of the proposed system for the classification of breast cancer on histopathological images

\subsection{Dataset}

In this study, experimental studies conducted for breast cancer classification were carried out on breast cancer e-ISSN: 2148-2683 histopathology images presented in publicly available Breast Histopathology Images dataset (Cruz-Roa et al., 2014; Janowczyk \& Madabhushi, 2016). The images in the original 
dataset consist of $277,52450 \times 50$ pixel patches extracted from 281 slide images of 281 breast cancer (BCa) specimens that were scanned at $40 \mathrm{X}$. Of the images obtained, 198,738 were diagnosed as invasive ductal carcinoma (IDC) negative, and 78,786 were diagnosed as IDC positive. Figure 2 denotes the IDC negative and positive sample images in the Breast Histopathology Images dataset
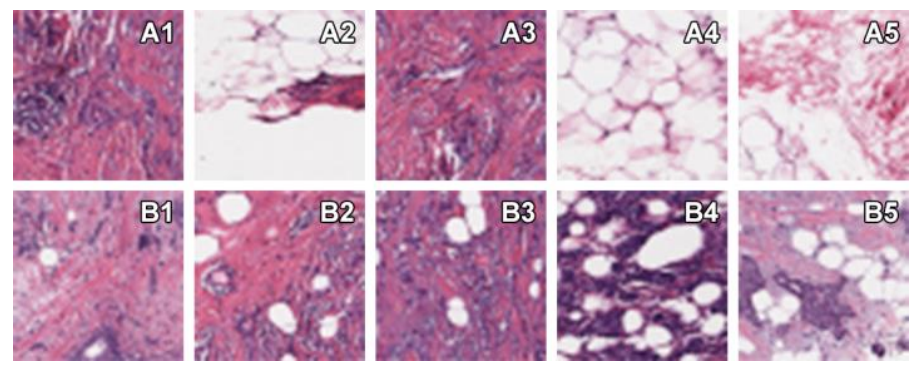

Figure 2. IDC (A1, $A 2, A 3, A 4, A 5)$ positive and IDC (B1, B2, $B 3, B 4, B 5)$ negative histopathological image samples in the breast histopathology dataset

\subsection{Feature Extraction and Feature Fusion}

In this stage of the study, texton features, network features, morphometric features and gray-level co-occurrence matrix (GLCM) features were extracted from the positive and negative histopathological images in the Breast Histopathology Images dataset and feature fusion was used for classification with BoW and DNN methods.

\subsubsection{Texton Features}

Khurd et al.(Khurd et al., 2010) proposed a texton classification system for the staging of prostate cancer. This feature extraction was called texton since a clustering-based filtering was applied to determine the basic level texton elements. An unchanged filter bank was used at each pixel level to extract texton features. For this feature extraction, the properties of the Maximum Response (MR) filter bank presented by Varma and Zisserman were obtained (Chekkoury et al., 2012). These filter banks are the MR8 filter, the Gaussian filter, and the Laplacian of Gaussian filter.

\subsubsection{Morphometric Features}

Within the scope of the study, the morphometric features determined for the histopathological images capture the variation in the size and shape of the cell nuclei on the image in accordance with the parameters determined by the pathologists (Bloom \& Richardson, 1957). By this feature extraction method, three different types of morphometric features were investigated such as information extracted from the Hessian matrix, information provided by the Fourier shape descriptors, and a special designed feature extracted by encoding the spatial arrangement of nuclei surrounding a ductal structure (Chekkoury et al., 2012).

\subsubsection{Network Features}

As in pattern recognition problems, edge connection patterns between pairs of points that make up objects on an image are very important. The network features used in this study were obtained from Urquhart graphs based on the relative neighborhood graph of cell nuclei detected from histopathological images (Andrade \& de Figueiredo, 2001). In the study, network cycles were used based on network statistics to capture special signals using Urquhart graphs and extra cellular matrices. In the experimental studies, related features were used depending on the weighted and unweighted lengths of different cycles.

\subsubsection{Gray-Level Co-occurrence Matrix (GLCM) Features}

The GLCM (gray-level co-occurrence matrix) features proposed by Haralick for the first time describe the statistical characteristics of a gray-level tissue (Clausi, 2002; Haralick et al., 1973). Relationships between pixels with different gray levels can be represented by GLCM features. If the image is two-dimensional (2D), features can be extracted from different GLCM direction angles. In this study, GLCM features extracted from histopathological H\&E images were obtained with $0^{0}, 45^{0}$, $90^{\circ}$ and $135^{\circ}$ angle directions and with a distance $(\mathrm{d}=2)$. GLCM features extracted from histopathological images for the classification of breast cancer are Angular Second Moment, Entropy, Dissimilarity, Contrast, Inverse Difference, Correlation, Homogeneity, Autocorrelation, Cluster Shade, Maximum probability, Cluster Prominence, Sum Average, Sum Entropy, Sum of Squares, Sum Variance, Difference Variance, Difference Entropy, Information measures of correlation-1, Information measures of correlation-2, Maximal correlation co-efficient, Inverse difference normalized, Inverse difference moment normalized, respectively.

\subsubsection{Feature Fusion}

In this study, feature fusion was performed for texton features, network features, morphometric features and GLCM features extracted from histopathological images, as seen in Figure 3. The feature set obtained from basal-like breast cancer images was classified by using the proposed hybrid method by combining with the BoW and DNN methods after the feature selection process

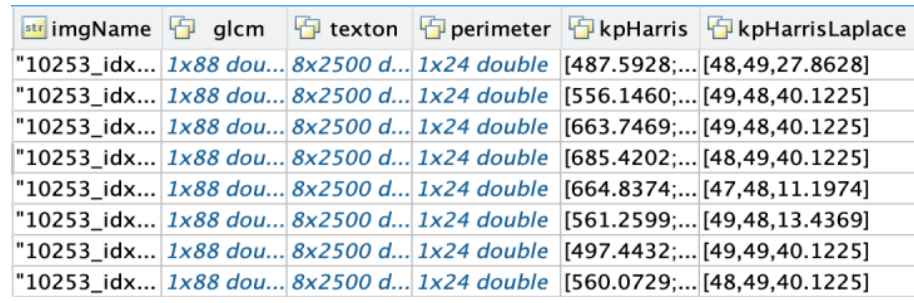

Figure 3. Feature fusion for the texton features, network features, morphometric features and GLCM features

\subsubsection{Feature Selection}

In the study, since the total number of texton features, network features, morphometric features and GLCM features extracted from histopathological images was very high, it was seen that the use of all of them together reduced the detection performance. For this reason, the most appropriate features were selected among the combined features. In the experimental studies, selection of appropriate features extracted from histopathological images was performed by Sequential Floating Forward Selection (SFFS) method via KNIME software (KNIME, 2021). SFFS is a general feature extraction method and is used to select the most effective features from large feature matrices according to the level of importance of features (Pudil et al., 1994). For feature selection, the architecture of block diagram shown in Figure 4 was designed by artificial neural networks in KNIME software. 


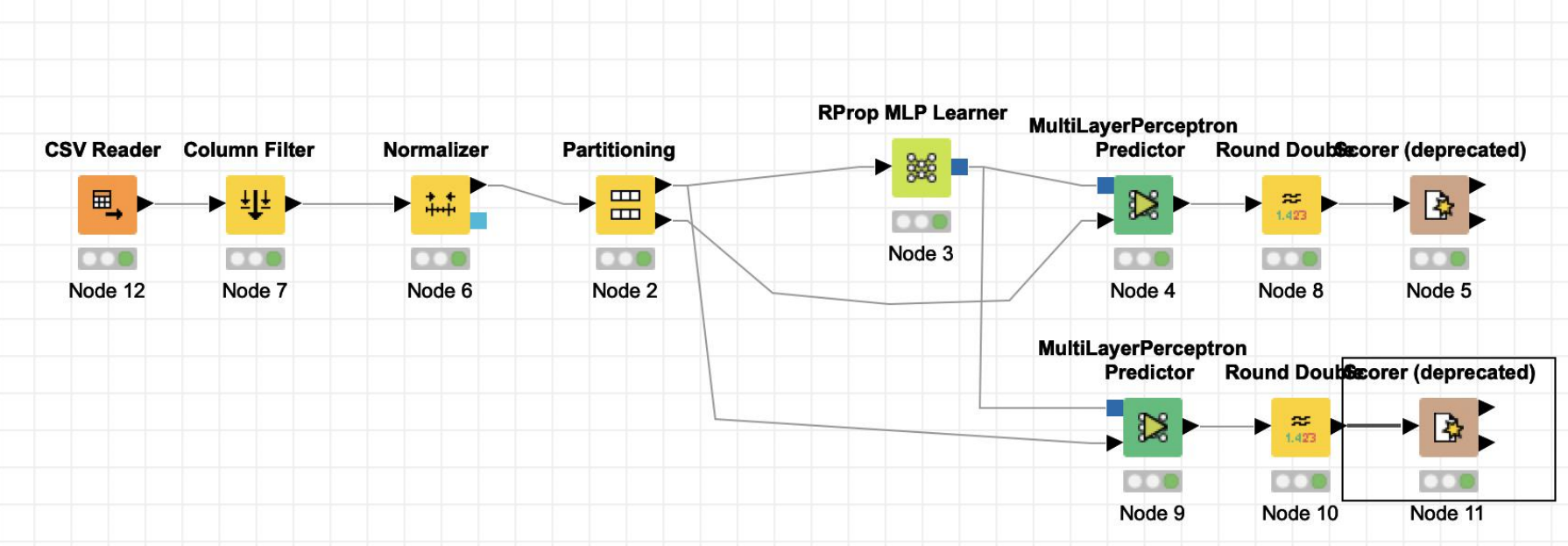

Figure 4. Block diagram designed in KNIME environment for feature selection

As a result of feature selection, the rank of each of the features was presented according to their importance in Figure 5. Therefore, the most appropriate features for the proposed hybrid method were selected and histopathological images were classified.

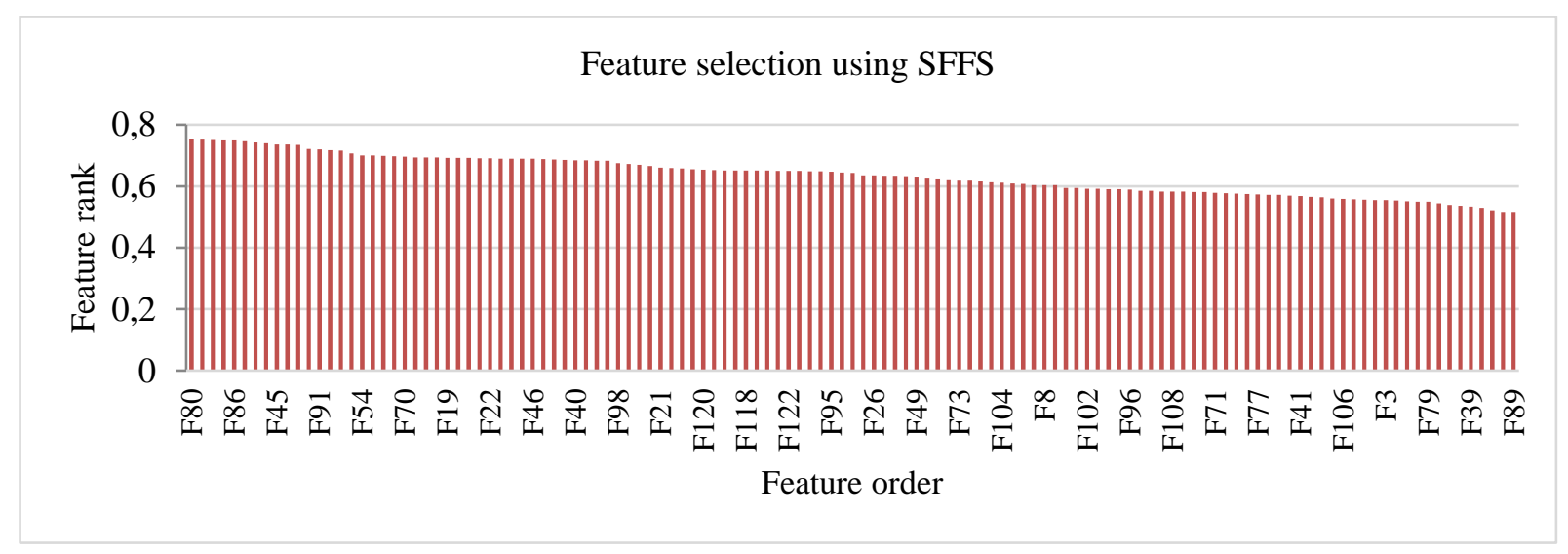

Figure 5. Ranking the features of importance

\subsection{Classification}

In the study, basal-like breast cancer classification based on feature fusion was performed by BoW and DNN methods, using texton features, network features, morphometric features and GLCM features extracted from histopathological images.

DNN is a different application of CNN architecture and is widely preferred in classification problems. DNN architecture also has similar features as 1D-CNN structure (Eren et al., 2019). In DNN architecture, the convolution layer used in CNN architectures is generally not used. Instead of this, dense layer is preferred. In this study, the DNN architecture was designed in the Python programming language using TensorFlow environment for the classification of the extracted features on the histopathological images, which is shown in Figure 6. The "adam" function was preferred as the optimizer in the designed DNN architecture.

Another method used in the study to create hybrid architecture is BoW, known as bag of words. The BoW model is a frequently used model in classification problems, especially in natural processing. The structure of BoW is derived from natural language processing and Information retrieval (Zhang et al., 2010). Today, BoW is widely used in the field of image processing. BoW represents an image as a set of features since e-ISSN: 2148-2683 the features on the image consist of key points and descriptors. In BoW, classification is performed by extracting the frequency histogram of the features in an image (Ali et al., 2015). Basically, BoW extracts the main feature of the images of the learned classes and converts them into a codebook to be used to compare the features of the images of the unknown classes to find the best class to represent the images of these unknown classes (Li et al., 2010). The block diagram showing the structure of the BoW algorithm in a classification problem is presented in Figure 7.

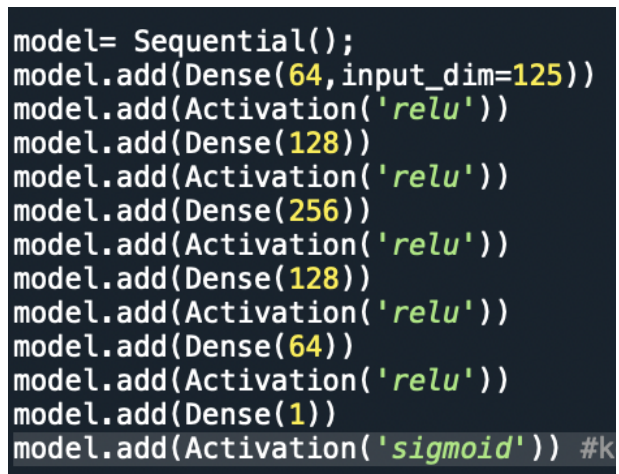

Figure 6. DNN architecture designed for classification of features extracted from histopathological images 


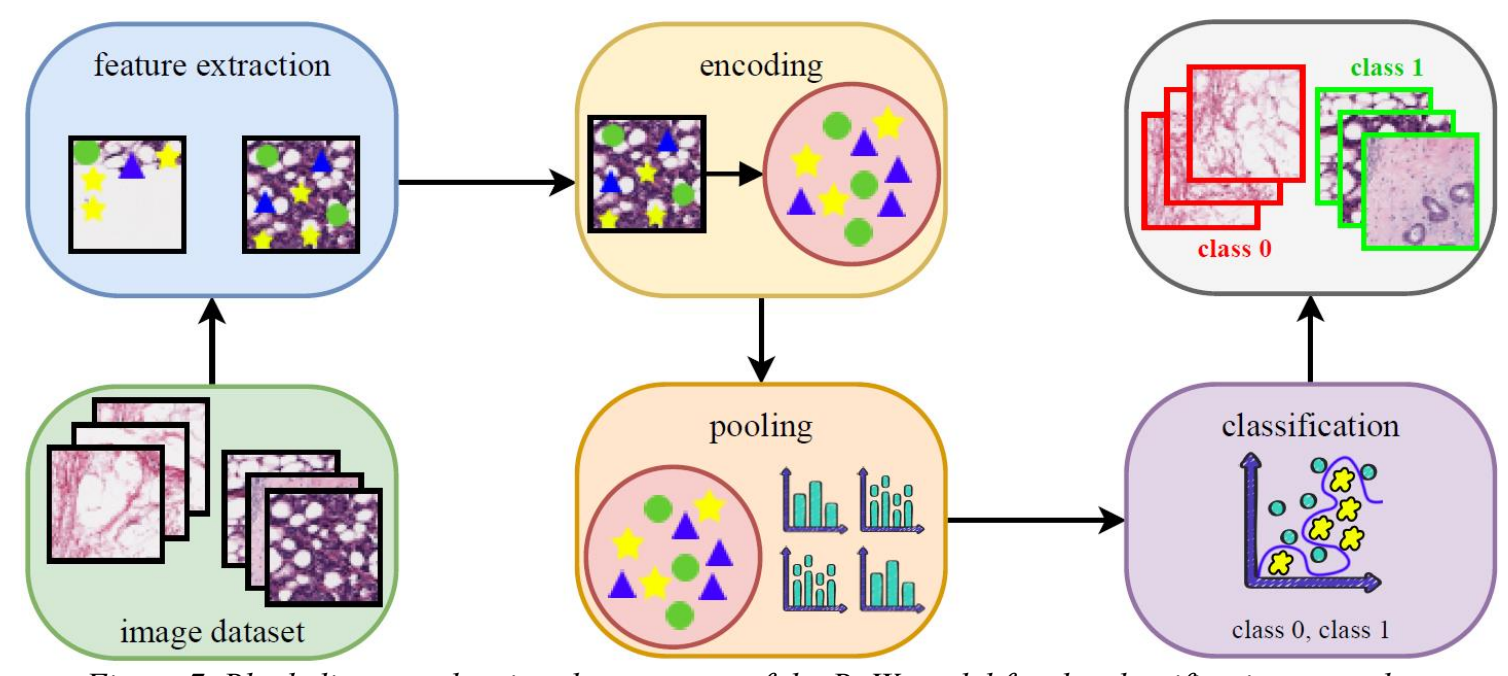

Figure 7. Block diagram showing the structure of the BoW model for the classification procedure

\section{Experimental Analysis}

In this study, many experimental studies were conducted to verify the performance of the proposed DNN and BoW-based hybrid method for the classification of breast cancer from histopathological images. Experimental analyzes were carried out by verifying the results and findings obtained as a result of experimental studies using measurement metrics. Experimental analyzes in this study were carried out using a desktop workstation computer with Asus Z390 motherboard, Intel Core i9-9900K $5 \mathrm{GHz}$ processor, 32GB RAM memory, NVIDIA GeForce RTX 2080Ti GPU, 256GB SSD hardware.

In the experimental studies, approximately $10 \%$ of the images in the Breast Histopathology Images dataset, which were diagnosed as 198,738 IDC negative (class 0), 78,786 IDC positive (class 1), were selected to be used in the study. A total of 12,423 images were randomly selected with a balanced class distribution. The selected dataset was divided into two subgroups as $80 \%$ (9938 images) for the training set and $20 \%$ (2485 images) for the test set. Experimental studies were carried out on these training and test sets.

In the experimental studies, feature fusion was performed for texton features, network features, morphometric features and GLCM features extracted from histopathological images. Basallike breast cancer classification was performed by a hybrid approach based on BoW and DNN methods. Experimental studies were first performed using the BoW method. When the most appropriate features selected by SFFS among the features combined with feature fusion were classified using BoW, an average accuracy rate of $67 \%$ was achieved depending on the IDC negative (class 0 ) and IDC positive (class 1 ) classes. In the second phase of the experimental studies, only the DNN method was applied using the appropriate features selected from the combined features for the classification of breast cancer from histopathological images. For IDC negative (class 0) and IDC positive (class 1) classes, an average accuracy rate of $74.16 \%$ was achieved using the DNN method.

In order to achieve higher classification accuracy than the accuracy scores achieved by using DNN-only and BoW-only methods, a hybrid (hybrid) approach based on BoW and DNN methods was used to classify selected features. Some parameter values achieved for the training phase conducted using the BoW and DNN hybrid method after feature fusion and selection are shown in Figure 8. In addition, the board screen showing the changes in the accuracy and loss values of the proposed hybrid network during training is presented in Figure 9. As can be seen from both figures, the average accuracy score for the proposed hybrid network tends to fall above $90 \%$ and the average loss value tends to fall to 0.1 . Therefore, it can be concluded that the training phase of the proposed network was successful.

\begin{tabular}{|c|c|c|c|c|c|c|c|c|c|c|c|c|}
\hline I & Epoch & $\begin{array}{l}1 \\
1\end{array}$ & Iteration & I & $\begin{array}{l}\text { Time } \\
\text { (hh: }\end{array}$ & $\begin{array}{l}\text { Elapsed } \\
\text { :mm:ss) }\end{array}$ & $\begin{array}{l}1 \\
1\end{array}$ & $\begin{array}{l}\text { Mini-batch } \\
\text { Accuracy }\end{array}$ & $\begin{array}{l}1 \\
1\end{array}$ & $\begin{array}{l}\text { Mini-batch } \\
\text { Loss }\end{array}$ & $\begin{array}{l}1 \\
1\end{array}$ & $\begin{array}{l}\text { Base Learning } \\
\text { Rate }\end{array}$ \\
\hline I & 1 & & 1 & 1 & & $00: 00: 03$ & 1 & $53.12 \frac{8}{8}$ & I & 0.8468 & 1 & 0.0010 \\
\hline I & 1 & I & 50 & I & & $00: 00: 38$ & I & $80.47 \%$ & 1 & 0.3865 & 1 & 0.0010 \\
\hline I & 2 & I & 100 & 1 & & $00: 01: 12$ & 1 & $83.59 \%$ & 1 & 0.3263 & 1 & 0.0010 \\
\hline I & 2 & I & 150 & I & & $00: 01: 47$ & I & $83.59 \frac{8}{8}$ & 1 & 0.4357 & 1 & 0.0010 \\
\hline I & 3 & 1 & 200 & 1 & & $00: 02: 23$ & 1 & $86.72 \%$ & I & 0.2370 & 1 & 0.0010 \\
\hline I & 4 & 1 & 250 & 1 & & $00: 02: 58$ & I & $82.81 \frac{8}{8}$ & I & 0.3422 & I & 0.0010 \\
\hline I & 4 & 1 & 300 & 1 & & $00: 03: 34$ & I & 92.198 & I & 0.2024 & I & 0.0010 \\
\hline I & 5 & I & 350 & I & & $00: 04: 10$ & I & $93.75 \%$ & 1 & 0.1733 & I & 0.0010 \\
\hline I & 6 & 1 & 400 & 1 & & $00: 04: 45$ & I & 96.098 & 1 & 0.1378 & 1 & 0.0010 \\
\hline I & 6 & 1 & 450 & I & & $00: 05: 20$ & 1 & $100.00 \%$ & I & 0.0636 & I & 0.0010 \\
\hline I & 7 & 1 & 500 & 1 & & $00: 05: 56$ & 1 & $90.62 \frac{8}{8}$ & I & 0.2104 & 1 & 0.0010 \\
\hline I & 8 & 1 & 550 & I & & $00: 06: 32$ & I & $92.19 \%$ & I & 0.1907 & I & 0.0010 \\
\hline I & 8 & I & 600 & 1 & & $00: 07: 07$ & I & $96.88 \%$ & I & 0.1052 & I & 0.0010 \\
\hline I & 9 & 1 & 650 & 1 & & $00: 07: 43$ & 1 & $92.97 \frac{8}{8}$ & I & 0.1623 & I & 0.0010 \\
\hline I & 9 & 1 & 700 & 1 & & $00: 08: 18$ & I & $92.97 \frac{8}{8}$ & I & 0.1823 & I & 0.0010 \\
\hline I & 10 & 1 & 750 & 1 & & $00: 08: 54$ & 1 & $90.62 \%$ & I & 0.2007 & 1 & 0.0010 \\
\hline I & 10 & I & 780 & 1 & & $00: 09: 15$ & I & $96.09 \frac{8}{8}$ & I & 0.1006 & I & 0.0010 \\
\hline
\end{tabular}

Figure 8. Some parameter values achieved for the training phase conducted using the BoW and DNN hybrid method 


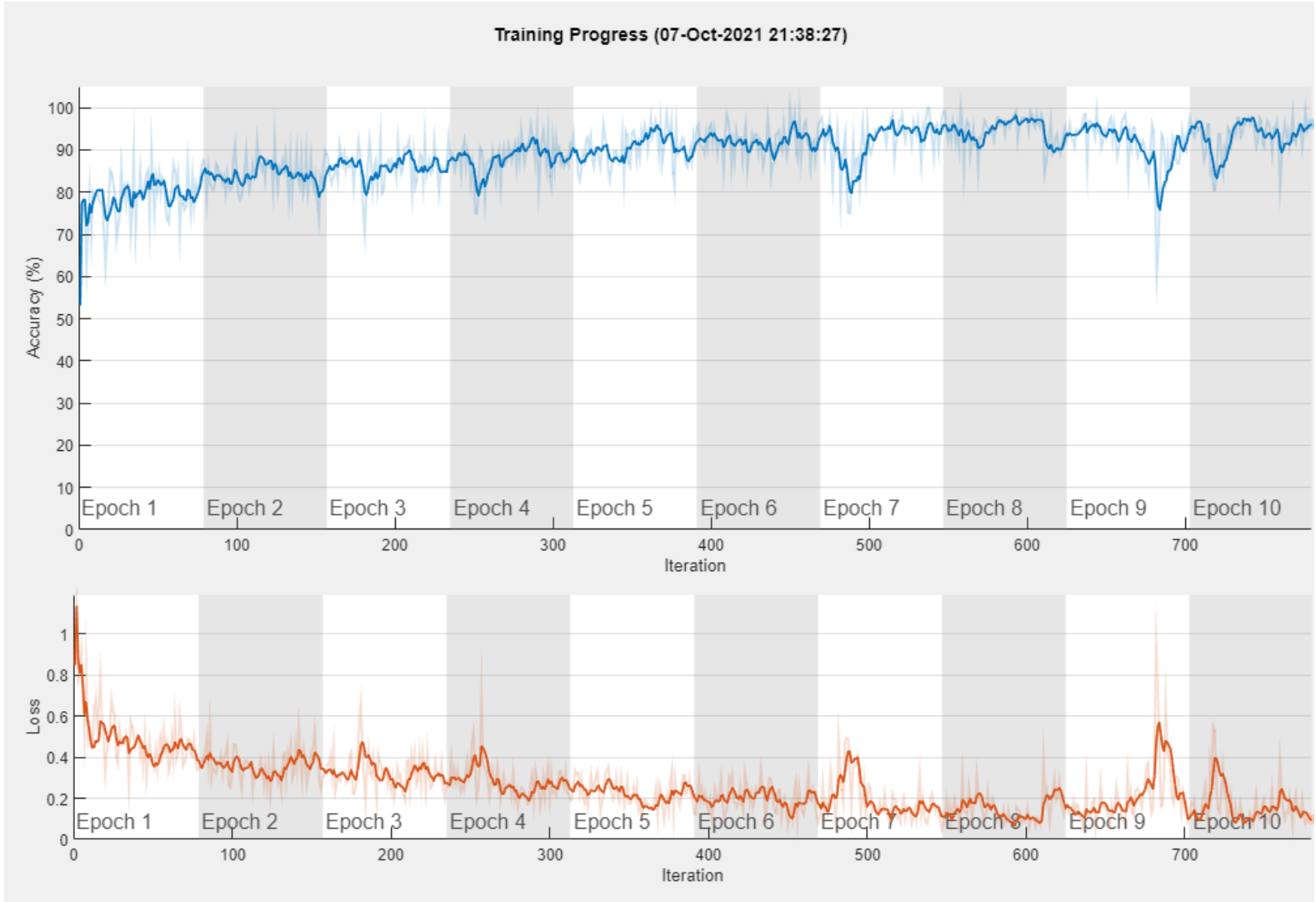

Figure 9. Board screen showing the changes in the accuracy and Loss values of the proposed hybrid network during training

The confusion matrices showing the classification results obtained on the training and test sets using the proposed hybrid method after the training phase is completed are shown in Table 2 and Table 3, respectively. As can be seen from these confusion matrices, $94.5 \%$ classification accuracy was achieved with the training dataset, while $80.8 \%$ classification accuracy was succeed with the test set.

Table 2. The confusion matrix showing the classification results obtained on the training set by the proposed hybrid method

\begin{tabular}{|c|c|c|c|c|}
\hline \multicolumn{5}{|c|}{ Train Accuracy Confusion Matrix } \\
\hline \multirow{2}{*}{ 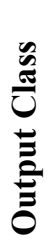 } & Class 0 & 7359 & 486 & $\begin{array}{c}93.8 \% \\
6.2 \%\end{array}$ \\
\hline & Class 1 & 63 & 2152 & $\begin{array}{c}97.2 \% \\
2.8 \%\end{array}$ \\
\hline & Accuracy & $99.2 \%$ & $81.6 \%$ & $94.5 \%$ \\
\hline & \multirow[t]{3}{*}{ Error } & $0.8 \%$ & $18.4 \%$ & $5.5 \%$ \\
\hline & & Class 0 & Class 1 & \\
\hline & & \multicolumn{2}{|c|}{ Target Class } & \\
\hline
\end{tabular}

Table 3. The complexity matrix showing the classification results obtained on the test set by the proposed hybrid method

\begin{tabular}{|c|c|c|c|c|}
\hline \multicolumn{5}{|c|}{ Test Accuracy Confusion Matrix } \\
\hline \multirow{2}{*}{ 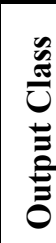 } & Class 0 & 1684 & 313 & $84.3 \%$ \\
\hline & Class 1 & 171 & 347 & $\begin{array}{l}67.0 \% \\
33.0 \%\end{array}$ \\
\hline & Accuracy & $90.8 \%$ & $52.6 \%$ & $80.8 \%$ \\
\hline & \multirow[t]{3}{*}{ Error } & $9.2 \%$ & $47.4 \%$ & $19.2 \%$ \\
\hline & & Class 0 & Class 1 & \\
\hline & & \multicolumn{2}{|c|}{ Target Class } & \\
\hline
\end{tabular}

\section{Conclusion}

The diagnosis of diseases in medical scans has some drawbacks as manual selection of the region of interest by experts, being open to human error, mostly being subjective/depending on experience, and causing unnecessary waste of time. In order to eliminate these problems, especially in recent years, the use of computer-aided secondary tools that help physicians in the decision-making process based on medical images for the diagnosis of many diseases, especially cancer has increased significantly. In this study, a hybrid method based on BoW and DNN methods is proposed to study the development 
of basal-like breast tumors and classify basal-like breast cancer types using histopathological images. In the study, first of all, useful texton features, network features, morphometric features and GLCM features that support accurate classification between tumor and non-tumor regions were extracted. Then after feature fusion was applied, the most appropriate features among all features were selected using SFFS. In the experimental studies performed using the proposed hybrid method based on the BoW and DNN methods, 94.5\% classification accuracy was achieved for the training dataset, while $80.8 \%$ classification accuracy score was obtained for the test set. The proposed method is presented with a secondary tool structure as a computer aided decision support system that can assist physicians in the classification of breast cancer. In future studies, it is planned to create a original dataset from histopathological images for the classification of breast cancer and to achieve a high accuracy score in the studies to be performed on this dataset.

\section{Acknowledgements}

This study was supported by Scientific Research Projects Department of Bilecik Seyh Edebali University with the project numbered 2019-01.BŞEÜ.25-02. The team would like to thank Scientific Research Projects Department of Bilecik Seyh Edebali University for their contributions. We also thank to providers of publicly-available datasets.

\section{References}

Abdel-Zaher, A. M., \& Eldeib, A. M. (2016). Breast cancer classification using deep belief networks. Expert Systems with Applications, 46, 139-144.

ACS. (2021). How Common Is Breast Cancer? Available: https://www.cancer.org/cancer/breastcancer/about/how-common-is-breast-cancer.html

Ali, N. M., Karis, M. S., Abidin, A. F. Z., Bakri, B., Shair, E. F., \& Razif, N. R. A. (2015). Traffic sign detection and recognition: Review and analysis. Jurnal Teknologi, $77(20)$.

Andrade, D. V., \& de Figueiredo, L. H. (2001). Good approximations for the relative neighbourhood graph. Paper presented at the CCCG.

Azar, A. T., \& El-Said, S. A. (2013). Probabilistic neural network for breast cancer classification. Neural Computing and Applications, 23(6), 1737-1751.

Badowska-Kozakiewicz, A. M., \& Budzik, M. P. (2016). Immunohistochemical characteristics of basal-like breast cancer. Contemporary Oncology, 20(6), 436.

Badve, S., et al. (2011). Basal-like and triple-negative breast cancers: a critical review with an emphasis on the implications for pathologists and oncologists. Modern Pathology, 24(2), 157-167.

Bloom, H., \& Richardson, W. (1957). Histological grading and prognosis in breast cancer: a study of 1409 cases of which 359 have been followed for 15 years. British journal of cancer, 11(3), 359.

Budak, Ü., Cömert, Z., Rashid, Z. N., Şengür, A., \& Çıbuk, M. (2019). Computer-aided diagnosis system combining FCN and Bi-LSTM model for efficient breast cancer detection from histopathological images. Applied Soft Computing, 85, 105765.
Chekkoury, A., et al. (2012). Automated malignancy detection in breast histopathological images. Paper presented at the Medical Imaging 2012: Computer-Aided Diagnosis.

Clausi, D. A. (2002). An analysis of co-occurrence texture statistics as a function of grey level quantization. Canadian Journal of remote sensing, 28(1), 45-62.

Cruz-Roa, A., et al. (2014). Automatic detection of invasive ductal carcinoma in whole slide images with convolutional neural networks. Paper presented at the Medical Imaging 2014: Digital Pathology.

Çevik, K. K., Dandil, E., Uzun, S., Yildirim, M. S., \& Selvi, A. O. (2021). 12 Detection of breast cancer using deep neural networks with transfer learning on histopathological images Artificial Intelligence for Data-Driven Medical Diagnosis (pp. 245-264): De Gruyter.

Dai, X., Li, T., Bai, Z., Yang, Y., Liu, X., Zhan, J., \& Shi, B. (2015). Breast cancer intrinsic subtype classification, clinical use and future trends. American journal of cancer research, 5(10), 2929.

Dandıl, E., \& Serin, Z. (2020). Derin Sinir Ağları Kullanarak Histopatolojik Görüntülerde Meme Kanseri Tespiti. Avrupa Bilim ve Teknoloji Dergisi, 451-463.

Eren, L., Ince, T., \& Kiranyaz, S. (2019). A generic intelligent bearing fault diagnosis system using compact adaptive 1D CNN classifier. Journal of Signal Processing Systems, 91(2), 179-189.

Han, Z., Wei, B., Zheng, Y., Yin, Y., Li, K., \& Li, S. (2017). Breast cancer multi-classification from histopathological images with structured deep learning model. Scientific Reports, 7(1), 1-10.

Haralick, R. M., Shanmugam, K., \& Dinstein, I. H. (1973). Textural features for image classification. IEEE Transactions on systems, man, and cybernetics(6), 610621.

Ibrahim, F., Thio, T. H. G., Faisal, T., \& Neuman, M. (2015). The application of biomedical engineering techniques to the diagnosis and management of tropical diseases: a review. Sensors, 15(3), 6947-6995.

Janowczyk, A., \& Madabhushi, A. (2016). Deep learning for digital pathology image analysis: A comprehensive tutorial with selected use cases. Journal of pathology informatics, 7.

Jones, C. E., Maben, J., Lucas, G., Davies, E. A., Jack, R. H., \& Ream, E. (2015). Barriers to early diagnosis of symptomatic breast cancer: a qualitative study of Black African, Black Caribbean and White British women living in the UK. BMJ open, 5(3).

Khameneh, F. D., Razavi, S., \& Kamasak, M. (2019). Automated segmentation of cell membranes to evaluate HER2 status in whole slide images using a modified deep learning network. Computers in biology and medicine, 110, 164-174.

Khurd, P., Bahlmann, C., Maday, P., Kamen, A., Gibbs-Strauss, S., Genega, E. M., \& Frangioni, J. V. (2010). Computer-aided Gleason grading of prostate cancer histopathological images using texton forests. Paper presented at the 2010 IEEE International Symposium on Biomedical Imaging: From Nano to Macro.

KNIME. (2021). Available: https://www.knime.com/

Kumar, A., et al. (2020). Deep feature learning for histopathological image classification of canine 
mammary tumors and human breast cancer. Information Sciences, 508, 405-421.

Li, T., Mei, T., Kweon, I.-S., \& Hua, X.-S. (2010). Contextual bag-of-words for visual categorization. IEEE Transactions on Circuits and Systems for Video Technology, 21(4), 381-392.

Mikhaylov, V., \& Bakhshiev, A. (2017). The system for histopathology images analysis of spinal cord slices. Procedia Computer Science, 103(C), 239-243.

Mohammed, M. A., Al-Khateeb, B., Rashid, A. N., Ibrahim, D. A., Abd Ghani, M. K., \& Mostafa, S. A. (2018). Neural network and multi-fractal dimension features for breast cancer classification from ultrasound images. Computers \& Electrical Engineering, 70, 871-882.

Nahid, A.-A., Mehrabi, M. A., \& Kong, Y. (2018). Histopathological breast cancer image classification by deep neural network techniques guided by local clustering. BioMed research international, 2018.

Öztürk, Ş., \& Akdemir, B. (2018). Application of feature extraction and classification methods for histopathological image using GLCM, LBP, LBGLCM, GLRLM and SFTA. Procedia Computer Science, 132, 40-46.

Öztürk, Ş., \& Akdemir, B. (2019). HIC-net: A deep convolutional neural network model for classification of histopathological breast images. Computers \& Electrical Engineering, 76, 299-310.

Pudil, P., Novovičová, J., \& Kittler, J. (1994). Floating search methods in feature selection. Pattern Recognition Letters, 15(11), 1119-1125.

Sertel, O., Lozanski, G., Shana'ah, A., \& Gurcan, M. N. (2010). Computer-aided detection of centroblasts for follicular lymphoma grading using adaptive likelihood-based cell segmentation. IEEE transactions on biomedical engineering, 57(10), 2613-2616.

Sudharshan, P., Petitjean, C., Spanhol, F., Oliveira, L. E., Heutte, L., \& Honeine, P. (2019). Multiple instance learning for histopathological breast cancer image classification. Expert Systems with Applications, 117, 103-111.

Sung, H., Ferlay, J., Siegel, R. L., Laversanne, M., Soerjomataram, I., Jemal, A., \& Bray, F. (2021). Global cancer statistics 2020: GLOBOCAN estimates of incidence and mortality worldwide for 36 cancers in 185 countries. CA: a cancer journal for clinicians, 2021(0), 0-41. doi:https://doi.org/10.3322/caac.21660

Wang, D., Khosla, A., Gargeya, R., Irshad, H., \& Beck, A. H. (2016). Deep learning for identifying metastatic breast cancer. arXiv preprint arXiv: 1606.05718 .

Yan, R., et al. (2020). Breast cancer histopathological image classification using a hybrid deep neural network. Methods, 173, 52-60.

Zewdie, E. T., Tessema, A. W., \& Simegn, G. L. (2021). Classification of breast cancer types, sub-types and grade from histopathological images using deep learning technique. Health and Technology, 1-14.

Zhang, Y., Jin, R., \& Zhou, Z.-H. (2010). Understanding bag-ofwords model: a statistical framework. International Journal of Machine Learning and Cybernetics, 1(1-4), 43-52. 